\title{
Pelvic Congestion Syndrome: Systematic Review of Treatment Success
}

\author{
Candace L. Brown, MA, MD ${ }^{1}$ Magda Rizer, MS, DO ${ }^{2}$ Ryan Alexander, DO ${ }^{3}$ \\ Emerson E. Sharpe III, MD ${ }^{4}$ Paul J. Rochon, $M^{5}$
}

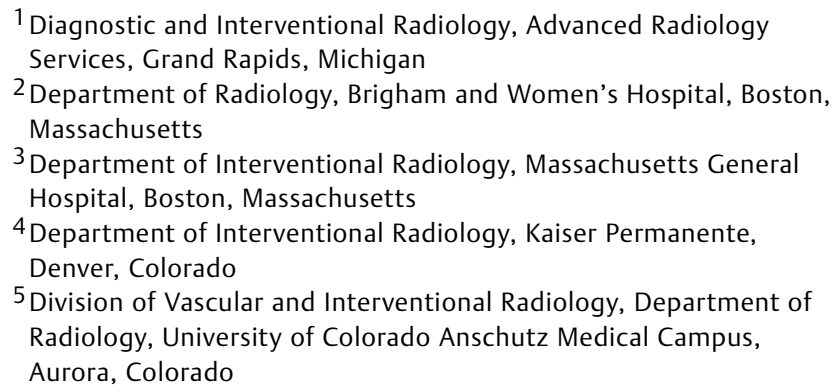

Address for correspondence Candace L. Brown, MA, MD, RPVI, Diagnostic and Interventional Radiology, Advanced Radiology Services, 3264 North Evergreen Dr., Grand Rapids, MI 49525 (e-mail: cbrown@advancedrad.com).

Semin Intervent Radiol 2018;35:35-40

\begin{abstract}
Keywords

- interventional radiology

- pelvic congestion syndrome

- pelvic pain

- venous reflux

- embolization

Pelvic venous insufficiency is now a well-characterized etiology of pelvic congestion syndrome (PCS). The prevalence of CPP is $15 \%$ in females aged 18 to 50 years in the United States and up to $43.4 \%$ worldwide. In addition to individual physical, emotional, and quality-of-life implications of CPP, there are profound healthcare and socioeconomic expenses with estimated annual direct and indirect costs in the United States in excess of 39 billion dollars. PCS consists of clinical symptoms with concomitant anatomic and physiologic abnormalities originating in venous insufficiency. The etiology of PCS is diverse involving both mechanical and hormonal factors contributing to venous dilatation ( $>5 \mathrm{~mm}$ ) and insufficiency. Factors affecting the diagnosis of PCS include variance of causes and clinical presentations of pelvic pain and relatively low sensitivity of noninvasive diagnostic imaging and laparoscopy to identify insufficiency compared with catheter venogram. A systematic review of the literature evaluating patient outcomes following percutaneous treatment of PCS is presented.
\end{abstract}

Objectives: Upon completion of this article, the reader will be able to describe the etiology of and risk factors contributing to the development of pelvic congestion syndrome. Readers will also be able to discuss the role of endovascular treatment for the disease process.

Accreditation: This activity has been planned and implemented in accordance with the accreditation requirements and policies of the Accreditation Council for Continuing Medical Education (ACCME) through the joint providership of Tufts University School of Medicine (TUSM) and Thieme Medical Publishers, New York. TUSM is accredited by the ACCME to provide continuing medical education for physicians.

Credit: Tufts University School of Medicine designates this journal-based CME activity for a maximum of 1 AMA
PRA Category 1 Credit $^{\mathrm{TM}}$. Physicians should claim only the credit commensurate with the extent of their participation in the activity.

Pelvic venous insufficiency, initially described around $1850 \mathrm{~s}^{1}$ and correlated with pelvic pain in the 1940 s to $1950 \mathrm{~s}^{2-4}$ is now a well-characterized etiology of pelvic congestion syndrome (PCS). ${ }^{1,5-7}$ Thirty percent to $40 \%$ of cases of chronic pelvic pain $(\mathrm{CPP})^{8}$ are associated with PCS. ${ }^{2,9}$ Prevalence of CPP is $15 \%$ in females aged 18 to 50 years in the United States ${ }^{10}$ and up to $43.4 \%$ worldwide. ${ }^{11-13} \mathrm{CPP}$ accounts for up to $40 \%$ of outpatient gynecologic visits ${ }^{14,15}$ and up to $40 \%$ of gynecologic laparoscopies. ${ }^{16}$ In addition to individual physical, emotional, and quality-of-life implications ${ }^{13}$ of CPP, there
Issue Theme Women's Health; Guest Editors, Kimi L. Kondo, DO, FSIR and Laura K. Findeiss, MD, FSIR
Copyright (C) 2018 by Thieme Medical Publishers, Inc., 333 Seventh Avenue, New York, NY 10001, USA. Tel: +1(212) 584-4662.
DOI https://doi.org/ 10.1055/s-0038-1636519. ISSN $0739-9529$. 
are profound healthcare and socioeconomic expenses with estimated annual direct and indirect costs in the United States in excess of 39 billion dollars. ${ }^{10,14}$

PCS consists of clinical symptoms with concomitant anatomic and physiologic abnormalities originating in venous insufficiency. ${ }^{17-19}$ Clinical symptoms of PCS are consistently reported as chronic, noncyclic pelvic pain or heaviness which is commonly exacerbated by prolonged standing and often occurring in association with dysmenorrhea, dyspareunia, urinary urgency, and perineal or lower extremity varices. $1,5,7,11,13,17,19-21$

The etiology of PCS is diverse involving both mechanical and hormonal factors contributing to venous dilatation (>5 mm) and insufficiency. ${ }^{7}$ Absence or dysfunction of valves, variant anatomy, venous kinking from uterine malposition, and structural and hormonal changes of parity all correspond to primary PCS, ${ }^{1,7,17,20}$ whereas extrinsic compression corresponds with secondary PCS. ${ }^{17}$ Slow flow, inflammation, thrombosis, and insufficiency are thought to be responsible for symptom development as pelvic varices can be present in asymptomatic individuals. ${ }^{7,22-25}$

Factors affecting the diagnosis of PCS include variance of causes and clinical presentations of pelvic pain ${ }^{1,2,20,26,27}$ and relatively low sensitivity of noninvasive diagnostic imaging and laparoscopy ${ }^{6,22}$ to identify insufficiency compared with catheter venogram. Despite diagnostic challenges, studies show promising results for percutaneous management of PCS delineating it as a treatable syndrome of significant prevalence, morbidity, and systemic costs. ${ }^{10,14,15,28}$ A systematic review of literature evaluating patient outcomes following percutaneous treatment of PCS is presented.

\section{Methods}

\section{Data Sources and Study Selection}

A systematic review of the MEDLINE database was conducted using PubMed, Ovid SP, and Google Scholar search engines. Methodologic framework followed PRISMA guidelines. ${ }^{29}$ Search parameters included full text articles published between 1974 and February 2015 using key words "pelvic congestion syndrome," "pelvic congestion," "pelvic varices," and "ovarian vein embolotherapy." Articles were manually reviewed for treatment of PCS, rendering 25 studies.

\section{Inclusion Criteria}

Inclusion criteria are as follows: (1) all studies with intervention for PCS with the method of intervention identified as percutaneous; (2) a minimum sample size of 10 study participants, excluding case reports or small case series; (3) studies that report assessment of patient symptoms pre- and posttreatment. Fourteen studies met inclusion criteria. $^{21,22,30-41}$

\section{Exclusion Criteria}

One study utilizing percutaneous ovarian vein embolization in patients with perineal and lower extremity varix without symptoms of PCS was excluded. Four studies utilizing surgical treatment were excluded. Six studies were excluded for having a sample population of less than 10 patients. Studies were excluded if the full text was not available. Review articles, letters, and editorials were also excluded.

\section{Quality Assurance and Appraisal}

Each eligible study was evaluated for methodology and potential bias.

\section{Data Extraction}

Included studies were reviewed to extract the following information from patient subsets undergoing percutaneous treatment for PCS: population size, study design, age, followup duration, type of intervention, embolic agent(s), and outcomes via change in pre- and posttreatment self-reported symptoms. Additional information including reported complications, symptom resolution, symptom type, parity, and postprocedure length of stay are reported according to the subset of studies providing these data points. Applicable PRISMA guidelines were followed in data collection, analysis, and reporting.

\section{Cumulative Data Synthesis}

Detailed description of extracted data was tabulated. Summary results are reported as proportions, medians (M) with corresponding interquartile range $\left(\mathrm{IQR}_{\mathrm{Q} 3-\mathrm{Q} 1}\right)$, or weighted means (average ${ }_{w}$ ), as applicable.

\section{Limitations of Review}

Studies meeting inclusion criteria for review are heterogeneous in method of treatment, endpoints, and in study populations and size precluding meta-analysis. Included studies consist of case series study design (lacking control groups). Use of subjective patient reporting to determine clinical success invites recall and interviewer bias. Nonetheless, there exist certain characteristics of patients, pitfalls, and percutaneous treatment, which are consistently described in the literature.

\section{Results}

\section{Study Demographics}

Fourteen studies of percutaneous treatment for PCS yield a total of 828 patients and 994 unique percutaneous interventions: 979 for initial sclerosis or embolization of ovarian or internal iliac veins (accounting for staged procedures), 21,22,30-41 14 repeat interventions for recurrent symptoms, ${ }^{30,34,40,41}$ and 1 repeat intervention for technical failure at initial intervention. ${ }^{41}$

Indication for intervention requires symptom(s) of PCS in combination with signs of pelvic venous incompetence on catheter-based venography. ${ }^{21,22,30-41}$

Average $_{\mathrm{w}}$ patient age is 40 years (range: 16-72 years). ${ }^{21,22,30-41}$

Average $_{\mathrm{w}}$ follow-up is 36.1 months (range: 1-288 months). ${ }^{21,22,30-41}$

Postprocedure length of stay ranges from 4 to 24 hours with procedures occurring in the outpatient setting $^{30,32,33,35,40,41}$ or overnight observation. ${ }^{21,22,37,40}$

Reported complications range from 0.85 to $10 \%$ (M: 4.95 , $\left.\mathrm{IQR}_{\mathrm{Q} 3-\mathrm{Q} 1}: 5.4\right)$ and were minor without sequelae: 6 cases of vessel perforation, 20 cases of nontarget embolization, 6 
groin hematomas, 1 arrhythmias, 1 internal iliac venous thrombus, and 2 contrast reactions among 944 unique procedures. $^{21,22,31,32,35-41}$

\section{Clinical Outcomes}

Patients reporting improvement of clinical symptoms following percutaneous treatment ranges from 68.3 to $100 \%$ (M: 95.1, $\left.\mathrm{IQR}_{\mathrm{Q} 3-\mathrm{Q} 1}: 17.4\right) .{ }^{21,22,30-41}$ of 828 patients, 762 (92\%) patients complete respective study follow-up endpoints. ${ }^{21,22,30-41}$ Following intervention, 697 (range: 68.3-100\%, M: 95.1, $\left.\mathrm{IQR}_{\mathrm{Q} 3-\mathrm{Q} 1}: 17.4\right)$ report some degree of symptomatic improvement, 57 (range: $0-31.7 \%, \mathrm{M}: 4.6, \mathrm{IQR}_{\mathrm{Q} 3-\mathrm{Q} 1}: 14.2$ ) report no symptom change, and 6 (range: $0-4.1 \%, \mathrm{M}: 0, \mathrm{IQR}_{\mathrm{Q} 3-\mathrm{Q} 1}: 0$ ) report worsening of symptoms. ${ }^{21,22,30-41}$ Of studies reporting resolution, 191 of 488 (range: $7.5-87.5 \%, \mathrm{M}: 58.2, \mathrm{IQR}_{\mathrm{Q} 3-\mathrm{Q} 1}$ : 27.1) report complete symptom resolution at followup. $21,30-34,37,41$

Of patients initially reporting symptom improvement, 18 (range: $0-18.2 \%, \mathrm{M}: 2.1, \mathrm{IQR}_{\mathrm{Q} 3-\mathrm{Q} 1}: 5.4$ ) report symptom recurrence occurring over a range from 4 to 12 months. ${ }^{21,22,30-32,34-36,38-41}$

\section{Repeat Interventions of Percutaneous and Surgical Natures}

Fourteen repeat percutaneous interventions were performed for recurrent symptoms: 1 case recurring 5 years after embolization following multiple pregnancies; ${ }^{34} 11$ cases recurring in venous territories not originally embolized; ${ }^{30,40,41}$ and 2 cases recurring in previously treated territories. $^{30}$ Follow-up of repeat interventions in these patients report improved symptoms for the patient experiencing recurrence following pregnancies ${ }^{34}$ and in two of five patients retreated for new or persistent varices. ${ }^{30}$

One study provides follow-up of nine patients undergoing hysterectomy due to lack of symptomatic improvement of pelvic pain following percutaneous treatment: hysterectomy yielded no additional symptom improvement. ${ }^{31}$

Kim et $\mathrm{al}^{22}$ reported a subset of 25 patients who failed to experience improvement of pelvic pain following hysterectomy, all 25 report symptomatic improvement following percutaneous treatment.

\section{Percutaneous Techniques}

Clinical improvement following coil embolization ranges from 82.1 to $100 \% \quad\left(\mathrm{M}: 95.8, \mathrm{IQR}_{\mathrm{Q} 3-\mathrm{Q} 1}: \quad 6.1\right)$ in 473patients. ${ }^{21,31,34,35,37-39}$ Clinical improvement following embolization with glue and lipiodized oil ranges from 68.3 to 73.7\% (M: 71, $\mathrm{IQR}_{\mathrm{Q} 3-\mathrm{Q} 1}: 5.4$ ) in 60 patients. ${ }^{30,32} \mathrm{~A}$ single study of isolated ovarian vein sclerosis reports $100 \%$ clinical success in 33 patients. ${ }^{33}$ Clinical success of studies involving mixed percutaneous methods including sclerosant with coil and/or Gelfoam embolization ranges from 83 to 100\% (M: 94.9, $\mathrm{IQR}_{\mathrm{Q} 3-\mathrm{Q} 1}: 17.1$ ) in 196 patients $^{22,36,40,41}$ (-Figs. 1-3).

\section{Territory of Intervention}

Six studies report treatment of ovarian veins with clinical improvement in 198 of 228 patients ranging from 68.3 to $100 \%\left(\mathrm{M}: 91.1, \mathrm{IQR}_{\mathrm{Q} 3-\mathrm{Q} 1}: 29\right) .{ }^{30-35}$ Five studies report treat-

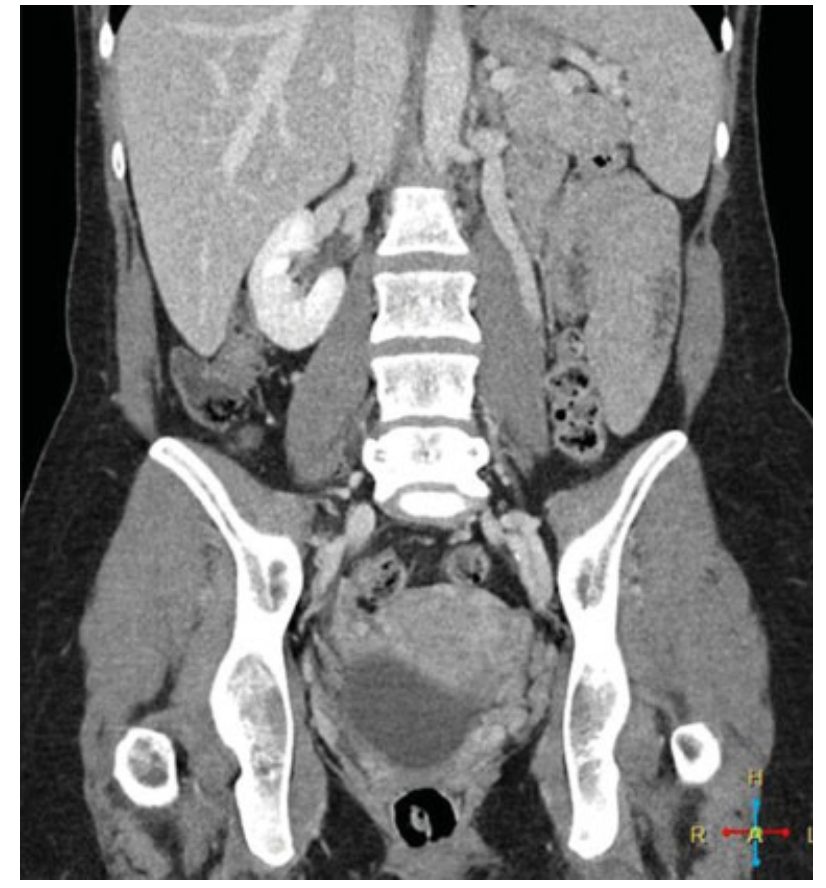

Fig. 1 Coronal CT venogram with dilated left gonadal vein.

ment of ovarian and internal iliac veins with clinical improvement in 334 of 348 patients ranging from 93.9 to 100\% (M: 95.8, IQR $\left.\mathrm{Q}_{\mathrm{Q}-\mathrm{Q} 1}: 5.9\right) .{ }^{21,36-39}$ Three studies report treatment of ovarian, internal iliac, and additional pelvic varices with clinical improvement in 165 of 186 patients ranging from 83 to $96 \%$ (M: 93.9, $\mathrm{IQR}_{\mathrm{Q} 3-\mathrm{Q} 1}: 13.4$ ). ${ }^{22,40,41}$

Studies specify 483 bilateral and 290 unilateral ovarian vein interventions, almost invariably left sided. ${ }^{21,22,30-35,37-40}$

\section{Variceal Diameter}

The diameter of ovarian veins based on catheter venogram ranges from 6.2 to $14.6 \mathrm{~mm}$; no correlation is identified comparing diameter to symptom improvement. ${ }^{21,31-35}$

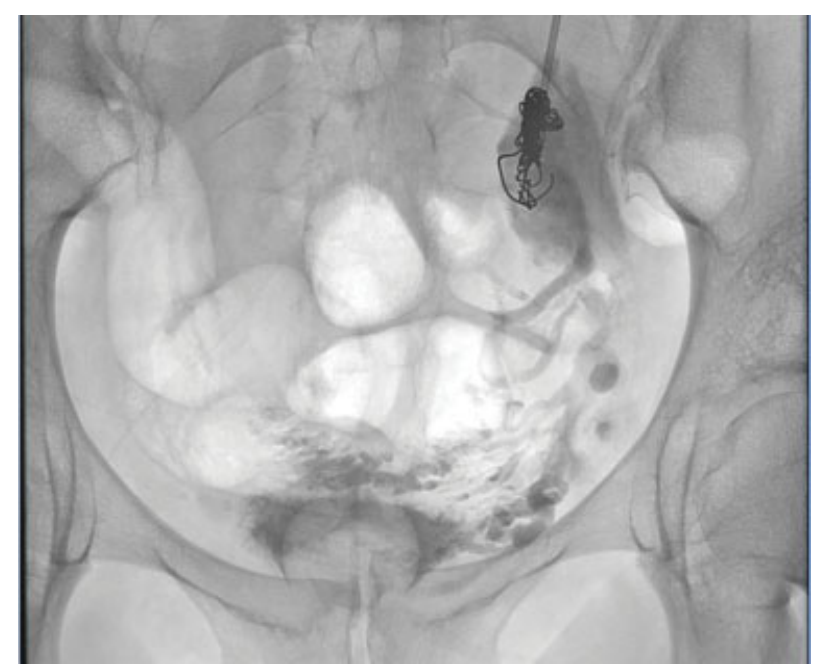

Fig. 2 Fluoroscopic view of the abdomen and pelvis demonstrates sodium tetradecyl sulfate and contrast in the deep pelvic varices with a coil in the left gonadal vein. 


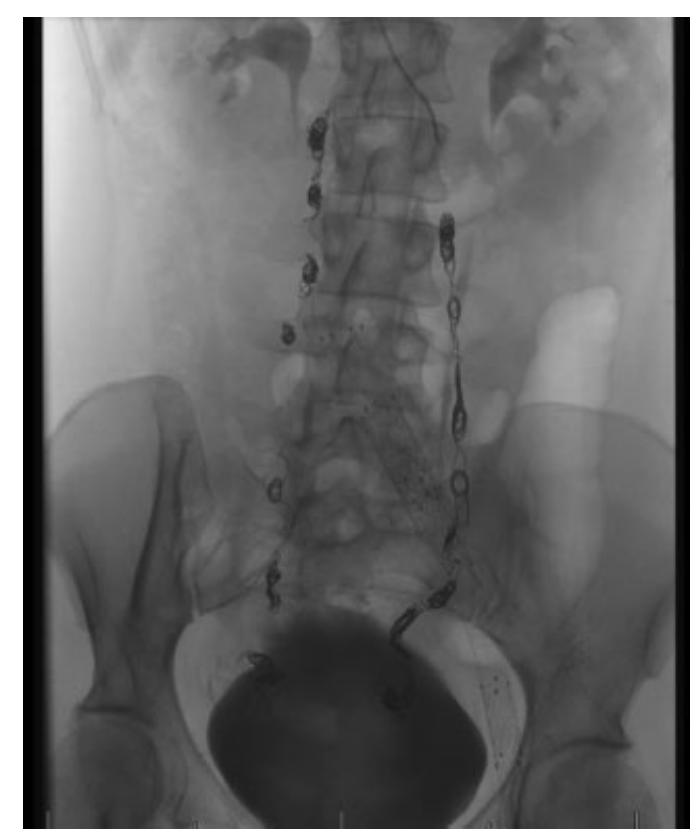

Fig. 3 Fluoroscopic view of the abdomen and pelvis demonstrates coils in the bilateral gonadal veins.

\section{Patient Assessment}

Studies utilize various endpoints to assess clinical success including patient report of symptom improvement, ${ }^{30,31}$ preand posttreatment questionnaires, ${ }^{32-34}$ decrease in variceal size, $^{30,33}$ and a VAS. ${ }^{21,22,35-41}$

\section{Parity}

Of 655 patients in studies reporting parity, 86.6\% were parous ${ }^{21,22,30-32,35-38}$ having an average $\mathrm{w}_{\mathrm{w}}$ parity of 2.6 (range: $0-8)^{21,30-32,35-39,41}$ Kwon et al $^{36}$ reported no statistically significant difference between parity (P1 through P5) and outcomes. Maleux et $\mathrm{al}^{32}$ reported no statistically significant difference in outcomes between multiparous and uniparous patients. Five studies include nulliparous patients, $22,30,35,39,41$ of which two studies having $21 \%^{30}$ and $63 \% 22$ nulliparous patients report no significant differences in outcomes between parous and nulliparous subpopulations.

\section{Symptom Breakdown}

From a total of 266 patients, $75.2 \%$ of patients report improvement of dysmenorrhea. ${ }^{21,37}$ From a total of 210 patients, $85.2 \%$ of patients report improvement of dyspareunia. $^{21,30,32-34,37,41}$ From a total of 149 patients, 98.7\% of patients report improvement of urinary urgency. $21,32,33,37$

\section{Discussion}

\section{Efficacy of Percutaneous Treatment in PCS}

Percutaneous embolization for PCS is an effective method of treatment having a high percentage of symptom improvement (reported in 697 of 762 patients). ${ }^{21,22,30-41}$ Studies utilizing a VAS as a quantitative measure of symptom improvement ${ }^{42}$ report statistically significant overall symptom improvement comparing posttreatment and pretreat- ment values with an average $e_{w}$ decrease of 5.7 within 0 to 10 scale. $^{21,22,35-41}$

\section{Safety}

Procedural complications in percutaneous treatment of PCS are minor and uncommon, reported in 36 of 944 procedures..$^{21,22,31,32,35-41}$ Reports of worsening symptoms after percutaneous treatment for PCS are rare, reported in 6 of 710 patients. ${ }^{22,31}$ No additional treatment-related sequelae were identified.

To date, no studies specifically address attempted conception following percutaneous treatment for PCS. Galkin et al reported a series of ovarian varix embolization to treat infertility, with improvement of clinical symptoms, laboratory tests, and 14 of 19 patients conceiving. ${ }^{43}$ Capasso et $\mathrm{al}^{31}$ reported no significant change in menstrual cycle posttreatment. Kim et $\mathrm{al}^{22}$ reported no change in pre- and postembolization levels of follicle-stimulating hormone, luteinizing hormone, or estradiol. Notably, percutaneous gonadal vein variceal embolization is recommended as treatment for both pain and infertility in the male population. ${ }^{44,45}$

\section{Interval of Clinical Improvement}

Studies reporting intervals of symptom change demonstrate improvement in the early postprocedural period ranging from 1 day to 3 months. ${ }^{30-32,35,38,40}$ A large-scale study with 5-year follow-up ${ }^{21}$ reports greatest decreases in VAS scores occurring within the first 6 months. Moreover, time frames may be falsely elevated reflecting documentation at the time of followup rather than time to symptom improvement.

Similarly, studies report little to no increase of symptom improvement beyond the early postprocedural period. Pieri et $\mathrm{al}^{34}$ reported changes in symptom levels and characteristics at 1-month follow-up, but no further changes at subsequent follow-up intervals. Kwon et $\mathrm{al}^{36}$ reported that for patients without symptom improvement during the initial 3 months, no improvement was experienced within the follow-up period. Chung and $\mathrm{Huh}^{35}$ and Nasser et al ${ }^{41}$ reported average VAS scores for follow-up intervals, showing marked improvement at 1-month follow-up with mild gradual improvement at 3, 6, and 12-month intervals.

\section{Recurrence, Reintervention, and Predictors}

Percutaneous intervention for PCS incurs minimal reported symptom recurrence, ${ }^{21,22,30-41}$ which may be artificially low compared with clinical practice given time frame of and reporting within studies. The majority of reported symptom recurrence occurs in territories not previously embolized. ${ }^{30,40,41}$

Repeat percutaneous intervention is sparsely reported with mixed results. ${ }^{30,34,40,41}$

Percutaneous treatment has been reported effective when prior interventions including hysterectomy ${ }^{22}$ and medication $^{29}$ have failed.

No consistent predictors of outcome following percutaneous intervention for PCS are identified within the studies. Specifically, parity, varix size, symptom severity, or territory embolized were not found to be independent predictors of outcome. 


\section{Percutaneous Technique}

Symptom improvement is similar between coil embolization, sclerosant, and combined use of agents, whereas that of glue and lipiodized oil is relatively lower.

\section{Treatment Territory}

Study techniques vary in territory and laterality of embolization, without accounting for different combinations of territories in reported results. There are divergent opinions as to whether limited ${ }^{30,31,39,41}$ or complete embolization $^{21,40}$ should be performed. Combination of ovarian, internal iliac, and additional variceal intervention ${ }^{22,40,41}$ has a range of clinical success lower than that of ovarian and iliac interventions, ${ }^{21,36-39}$ though median values are similar between these groups and isolated ovarian intervention. ${ }^{30-35}$

Studies reporting outcomes analysis comparing unilateral and bilateral embolization ${ }^{30,32}$ report no statistically significant difference. Capasso et $\mathrm{al}^{31}$ noted that $76.9 \%$ of patients treated with left ovarian vein embolization did not develop right ovarian varices at follow-up.

\section{Pitfalls of Diagnosis}

Patients with PCS are generally described as multiparous and premenopausal with reports of symptom resolution occurring at menopause. ${ }^{19,31,32}$ Five studies include nulliparous patients $22,30,35,39,41$ and no statistical difference in outcomes is identified based on number of pregnancies or between parous and nulliparous patients. ${ }^{22,30-32}$ Eight studies include patients aged 56 years and older ${ }^{21,30-33,39-41}$ exceeding an average age of postmenopausal patients as determined by a large-scale population study ${ }^{46}$ Nulliparous and postmenopausal patients present with PCS and these populations should not be overlooked.

Imaging findings of PCS are well described by Knuttinen et al including dilated ovarian, pelvic, arcuate, perineal, and lower extremity veins demonstrating slow flow, stasis, or reflux. ${ }^{18}$ However, studies report insensitivity of noninvasive imaging compared with catheter venogram. Cross-sectional imaging has a wide variance of reported sensitivities for detection of pelvic varices including, $12.5 \%$ on $\mathrm{CT}^{22}$ and 58.6 to $100 \%$ on MRI, ${ }^{18,22,47,48}$ related to venous drainage with supine positioning and lack of dynamic imaging sequences. ${ }^{119,20,40}$ Ultrasound offers advantages in dynamic and positional image acquisition allowing demonstration of venous reflux with upright positioning and Valsalva maneuver, ${ }^{49}$ yet studies report insensitivity ${ }^{50}$ compared with catheter venography with ultrasound identification of varices in as little as $53 \%{ }^{51}$ and $20 \% 22$ of cases. Diagnostic laparoscopy underestimates the presence and number of varices as both positioning and insufflation pressure facilitate drainage or effacement of varices ${ }^{40,50}$ with reports of pelvic variceal identification ranging from less than $20 \%{ }^{6}$ to $40 \%{ }^{22}$

Adding to diagnostic confusion, ovarian vein dilatation, though associated ${ }^{52}$ and predictive, ${ }^{18}$ is not synonymous with venous incompetence or symptoms. ${ }^{22-25}$

\section{Conclusion}

PCS is a prevalent and treatable condition for which percutaneous treatment is safe and effective. Thorough clinical and imaging evaluation by a provider who is familiar with the associated diagnostic pitfalls is imperative, as the indication for treatment of PCS requires both clinical symptom(s) and associated venous incompetence. Catheter-directed venography demonstrates improved sensitivity in detecting venous insufficiency compared with noninvasive imaging, as well as the benefit of simultaneous diagnosis and treatment, and a high rate of success in improving clinical symptoms.

\section{References}

1 Ganeshan A, Upponi S, Hon LQ, Uthappa MC, Warakaulle DR, Uberoi R. Chronic pelvic pain due to pelvic congestion syndrome: the role of diagnostic and interventional radiology. Cardiovasc Intervent Radiol 2007;30(06):1105-1111

2 Duncan $\mathrm{CH}$, Taylor HC Jr. A psychosomatic study of pelvic congestion. Am J Obstet Gynecol 1952;64(01):1-12

3 Taylor HC Jr. Vascular congestion and hyperemia; their effect on function and structure in the female reproductive organs; the clinical aspects of the congestion-fibrosis syndrome. Am J Obstet Gynecol 1949;57(04):637-653

4 Taylor HC. Pelvic pain based on a vascular and autonomic nervous system disorder. Am J Obstet Gynecol 1954;67(06):1177-1196

5 Beard RW, Reginald PW, Wadsworth J. Clinical features of women with chronic lower abdominal pain and pelvic congestion. Br J Obstet Gynaecol 1988;95(02):153-161

6 Beard RW, Highman JH, Pearce S, Reginald PW. Diagnosis of pelvic varicosities in women with chronic pelvic pain. Lancet 1984;2 (8409):946-949

7 Phillips D, Deipolyi AR, Hesketh RL, Midia M, Oklu R. Pelvic congestion syndrome: etiology of pain, diagnosis, and clinical management. J Vasc Interv Radiol 2014;25(05):725-733

8 Beard RW, Kennedy RG, Gangar KF, et al. Bilateral oophorectomy and hysterectomy in the treatment of intractable pelvic pain associated with pelvic congestion. Br J Obstet Gynaecol 1991;98 (10):988-992

9 Soysal ME, Soysal S, Vicdan K, Ozer S. A randomized controlled trial of goserelin and medroxyprogesterone acetate in the treatment of pelvic congestion. Hum Reprod 2001;16(05):931-939

10 Mathias SD, Kuppermann M, Liberman RF, Lipschutz RC, Steege JF. Chronic pelvic pain: prevalence, health-related quality of life, and economic correlates. Obstet Gynecol 1996;87(03):321-327

11 Latthe P, Latthe M, Say L, Gülmezoglu M, Khan KS. WHO systematic review of prevalence of chronic pelvic pain: a neglected reproductive health morbidity. BMC Public Health 2006;6:177-183

12 Ahangari A. Prevalence of chronic pelvic pain among women: an updated review. Pain Physician 2014;17(02):E141-E147

13 Zondervan KT, Yudkin PL, Vessey MP, et al. The community prevalence of chronic pelvic pain in women and associated illness behaviour. Br J Gen Pract 2001;51(468):541-547

14 Kuligowska E, Deeds L III, Lu K III. Pelvic pain: overlooked and underdiagnosed gynecologic conditions. Radiographics 2005;25 (01):3-20

15 Klock S. Psychosomatic issues in obstetrics and gynecology. In: Ryan KJ, Barbieri RL, eds. Gynecology Principles and Practice. St. Louis: Mosby; 1995:399-402

16 Howard FM. The role of laparoscopy in chronic pelvic pain: promise and pitfalls. Obstet Gynecol Surv 1993;48(06):357-387

17 Durham JD, Machan L. Pelvic congestion syndrome. Semin Intervent Radiol 2013;30(04):372-380 
18 Knuttinen MG, Xie K, Jani A, Palumbo A, Carrillo T, Mar W. Pelvic venous insufficiency: imaging diagnosis, treatment approaches, and therapeutic issues. AJR Am J Roentgenol 2015;204(02):448-458

19 Koo S, Fan CM. Pelvic congestion syndrome and pelvic varicosities. Tech Vasc Interv Radiol 2014;17(02):90-95

20 Ignacio EA, Dua R, Sarin S, et al. Pelvic congestion syndrome: diagnosis and treatment. Semin Intervent Radiol 2008;25(04): 361-368

21 Laborda A, Medrano J, de Blas I, Urtiaga I, Carnevale FC, de Gregorio MA. Endovascular treatment of pelvic congestion syndrome: visual analog scale (VAS) long-term follow-up clinical evaluation in 202 patients. Cardiovasc Intervent Radiol 2013;36 (04):1006-1014

22 Kim HS, Malhotra AD, Rowe PC, Lee JM, Venbrux AC. Embolotherapy for pelvic congestion syndrome: long-term results. J Vasc Interv Radiol 2006;17(2, Pt 1):289-297

23 Dos Santos SJ, Holdstock JM, Harrison CC, Lopez AJ, Whiteley MS. Ovarian vein diameter cannot be used as an indicator of ovarian venous reflux. Eur J Vasc Endovasc Surg 2015;49(01):90-94

24 Nascimento AB, Mitchell DG, Holland G. Ovarian veins: magnetic resonance imaging findings in an asymptomatic population. J Magn Reson Imaging 2002;15(05):551-556

25 Rozenblit AM, Ricci ZJ, Tuvia J, Amis ES Jr. Incompetent and dilated ovarian veins: a common CT finding in asymptomatic parous women. AJR Am J Roentgenol 2001;176(01):119-122

26 Latthe P, Mignini L, Gray R, Hills R, Khan K. Factors predisposing women to chronic pelvic pain: systematic review. BMJ 2006;332 (7544):749-755

27 Stones RW, Price C. Health services for women with chronic pelvic pain. J R Soc Med 2002;95(11):531-535

28 Cheong YC, Smotra G, Williams AC. Non-surgical interventions for the management of chronic pelvic pain. Cochrane Database Syst Rev 2014;3(03):CD008797

29 Moher D, Liberati A, Tetzlaff J, Altman DG; PRISMA Group. Preferred reporting items for systematic reviews and meta-analyses: the PRISMA statement. PLoS Med 2009;6(07):e1000097

30 Meneses L, Fava M, Diaz P, et al. Embolization of incompetent pelvic veins for the treatment of recurrent varicose veins in lower limbs and pelvic congestion syndrome. Cardiovasc Intervent Radiol 2013;36(01):128-132

31 Capasso P, Simons C, Trotteur G, Dondelinger RF, Henroteaux D, Gaspard U. Treatment of symptomatic pelvic varices by ovarian vein embolization. Cardiovasc Intervent Radiol 1997;20(02): 107-111

32 Maleux G, Stockx L, Wilms G, Marchal G. Ovarian vein embolization for the treatment of pelvic congestion syndrome: long-term technical and clinical results. J Vasc Interv Radiol 2000;11(07): 859-864

33 Venbrux AC, Chang AH, Kim HS, et al. Pelvic congestion syndrome (pelvic venous incompetence): impact of ovarian and internal iliac vein embolotherapy on menstrual cycle and chronic pelvic pain. J Vasc Interv Radiol 2002;13(2, Pt 1):171-178

34 Pieri S, Agresti P, Morucci M, de' Medici L. Percutaneous treatment of pelvic congestion syndrome. Radiol Med (Torino) 2003; 105(1-2):76-82

35 Chung MH, Huh CY. Comparison of treatments for pelvic congestion syndrome. Tohoku J Exp Med 2003;201(03):131-138
36 Kwon SH, Oh JH, Ko KR, Park HC, Huh JY. Transcatheter ovarian vein embolization using coils for the treatment of pelvic congestion syndrome. Cardiovasc Intervent Radiol 2007;30(04): 655-661

37 Creton D, Hennequin L, Kohler F, Allaert FA. Embolisation of symptomatic pelvic veins in women presenting with non-saphenous varicose veins of pelvic origin - three-year follow-up. Eur J Vasc Endovasc Surg 2007;34(01):112-117

38 Asciutto G, Asciutto KC, Mumme A, Geier B. Pelvic venous incompetence: reflux patterns and treatment results. Eur J Vasc Endovasc Surg 2009;38(03):381-386

39 Hocquelet A, Le Bras Y, Balian E, et al. Evaluation of the efficacy of endovascular treatment of pelvic congestion syndrome. Diagn Interv Imaging 2014;95(03):301-306

40 Nemark AI, Shelkovnikova NV. Endovascular treatment of persistent dysuria and chronic pelvic pain in women with pelvic varicose veins [in Russian]. Urologiia 2012;4(04):20-24

41 Nasser F, Cavalcante RN, Affonso BB, Messina ML, Carnevale FC, de Gregorio MA. Safety, efficacy, and prognostic factors in endovascular treatment of pelvic congestion syndrome. Int J Gynaecol Obstet 2014;125(01):65-68

42 Grossman SA, Sheidler VR, McGuire DB, Geer C, Santor D, Piantadosi S. A comparison of the Hopkins Pain Rating Instrument with standard visual analogue and verbal descriptor scales in patients with cancer pain. J Pain Symptom Manage 1992;7(04):196-203

43 Galkin EV, Grakova LS, Naumova EB. Roentgeno-endovascular surgery of hypofunctional ovaries in varicosities of the ovarian veins [in Russian]. Vestn Rentgenol Radiol 1991;5(05):51-59

44 Bittles MA, Hoffer EK. Gonadal vein embolization: treatment of varicocele and pelvic congestion syndrome. Semin Intervent Radiol 2008;25(03):261-270

45 Practice Committee of the American Society for Reproductive Medicine. Report on varicocele and infertility. Fertil Steril 2006; 86(05, Suppl 1):S93-S95

46 Triebner K, Johannessen A, Puggini L, et al. Menopause as a predictor of new-onset asthma: a longitudinal Northern European population study. J Allergy Clin Immunol 2015;6749(15): 1243-1249

47 Asciutto G, Mumme A, Marpe B, Köster O, Asciutto KC, Geier B. MR venography in the detection of pelvic venous congestion. Eur J Vasc Endovasc Surg 2008;36(04):491-496

48 Yang DM, Kim HC, Nam DH, Jahng GH, Huh CY, Lim JW. Timeresolved MR angiography for detecting and grading ovarian venous reflux: comparison with conventional venography. $\mathrm{Br} \mathrm{J}$ Radiol 2012;85(1014):e117-e122

49 Giacchetto C, Cotroneo GB, Marincolo F, Cammisuli F, Caruso G, Catizone F. Ovarian varicocele: ultrasonic and phlebographic evaluation. J Clin Ultrasound 1990;18(07):551-555

50 Liddle AD, Davies AH. Pelvic congestion syndrome: chronic pelvic pain caused by ovarian and internal iliac varices. Phlebology 2007;22(03):100-104

51 Park SJ, Lim JW, Ko YT, et al. Diagnosis of pelvic congestion syndrome using transabdominal and transvaginal sonography. AJR Am J Roentgenol 2004;182(03):683-688

52 Belenky A, Bartal G, Atar E, Cohen M, Bachar GN. Ovarian varices in healthy female kidney donors: incidence, morbidity, and clinical outcome. AJR Am J Roentgenol 2002;179(03):625-627 